\title{
THREE NEW PARASITIC NEMATODE WORMS
}

\section{By Mary Scott Skinker}

Junior Zoologist, Zoological Division, Bureau of Animal Industry, United States Department of Agriculture

The nematodes described in this paper are from three sources. The' first one, a species of Metabronema, is from a fish host and was collected by Mrs. M. Q. Bowman, of the Amory-Smithsonian expedition, from the region of the Matamek River, Province of Quebec, Canada. The specimens of Passalurus were collected by R. G. Meader of Hamilton College, Clinton, N. Y. Those designated as Metathelazia were collected by Dr. M. C. Hall and Dr. Eloise B. Cram, of the zoological division, from viscera forwarded to the Bureau of Animal Industry by F. W. Koehler, of the Bureau of Biological Survey.

\section{Family SPIRURIDAE Oerley, 1855}

Subfamily SPIRURINAE Railliet, 1915

METABRONEMA CANADENSE, new species

Figures 1 to 6

Specific diagnosis.-Metabronema: The head measures $38 \mu$ to $40 \mu$ in diameter. Oral aperture simple. The esophagus varies in length from $2.135 \mathrm{~mm}$. to $2.8 \mathrm{~mm}$. Transverse cuticular striations are conspicuous in the anterior fifth of the body, the distance between them being about $5 \mu$. The nerve ring is situated near the anterior end of the esophagus, about $60 \mu$ from the posterior end of the vestibule. Cervical papillae were not observed.

Male, $5.8 \mathrm{~mm}$. to $7.1 \mathrm{~mm}$. in length with a maximum diameter of $205 \mu$. The anterior portion of the esophagus is $900 \mu$ to $960 \mu$ long; the posterior portion is about $1.27 \mathrm{~mm}$. long. The tail is spirally coiled, making two or three complete coils. Caudal alae are conspicuous and are provided with four pairs of pedunculated preanal papillae, the posterior pair being located close to the cloacal opening. The spicules are unequal, the right one $330 \mu$ long, the left $115 \mu$ long.

Female, $9.5 \mathrm{~mm}$. to $10.4 \mathrm{~mm}$. long, with a diameter at the vulva of about $150 \mu$. The anterior portion of the esophagus is about $800 \mu$ long, the posterior portion about $2 \mathrm{~mm}$. long. The vulva is located

No. 2890.-Proceedings U. S. National Museum, Vol. 79, Art. 24. 
The slender portion of the tail is $152 \mu$ long. Two ovaries are present. The eggs are thin shelled and $85 \mu$ to $129 \mu$ long and about $60 \mu$ wide; they are unsegmented.
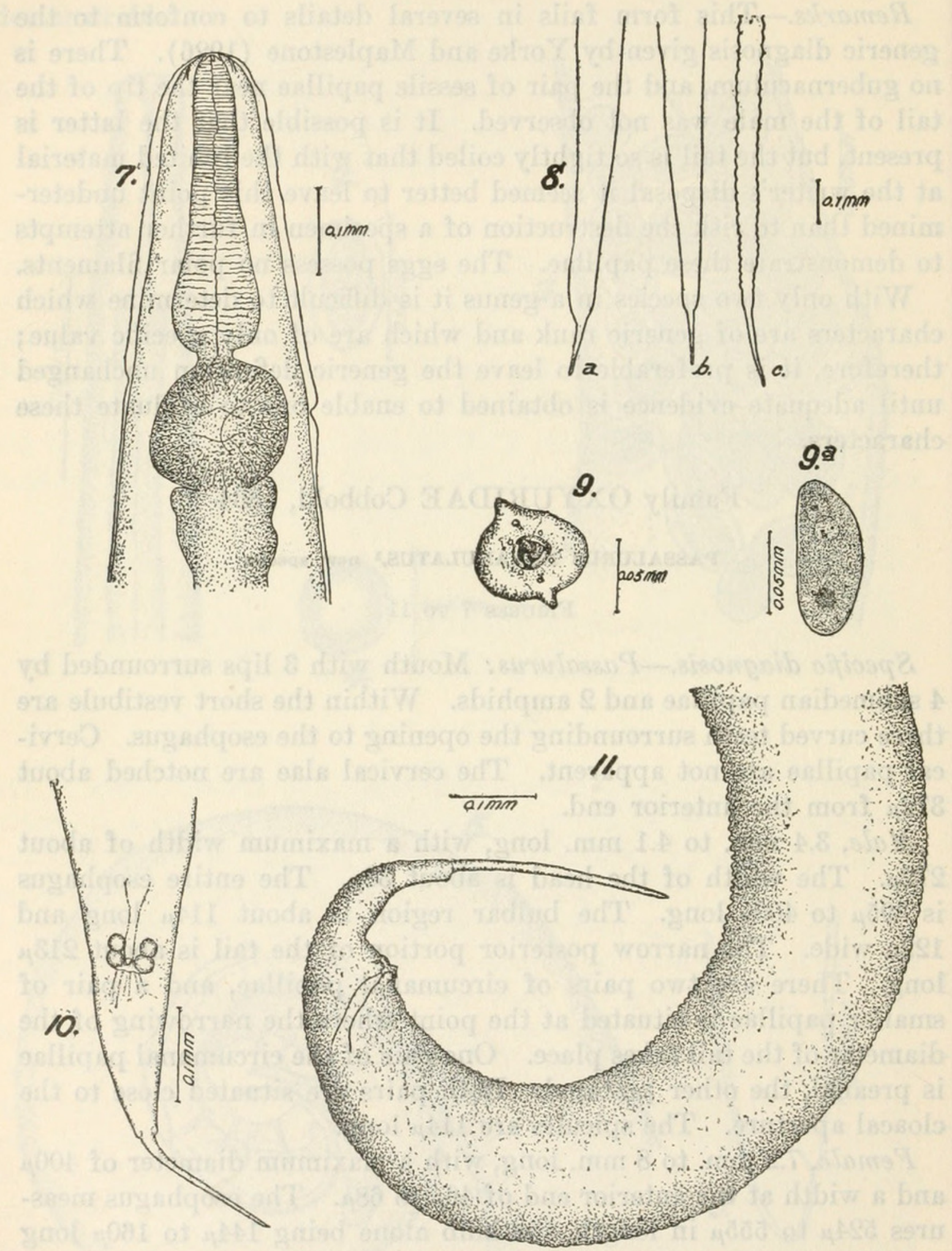

Figures 7-8b.-Passalurus nonanulatus: 7, Anterior end of male; 8a, posterior end of female from Canis lestes; $8 \mathrm{~b}$, posterior end of female from Lepus americanus Figure 8c.-Passalurus ambiguus: Posterior end of female, showing the moniliform condition

Figures 9-11.-Passalurus nonamilatus: 9, En face view ; 9a, egg ; 10, posterior end of male, ventral view; 11 , posterior end of male, lateral view 
Hosts.-American varying hare (Lepus americanus), coyote (Canis lestes). ${ }^{2}$

Location.-Small intestine.

Distribution.-United States (Cheboygan County, Mich., and Olympia, Wash.).

Type specimen.-U.S.N.M. Helm. Coll. No. 28463.

Remarks.-This species lacks the annulations found on the tail in mature females of Passalurus ambigurs. It is impossible, however, to determine in all cases in the earlier literature whether the author was describing a form in which the mature females possessed a moniliform tail. Both Schneider (1866) and von Linstow (1899), as well as Rudolphi (1819), fail to mention annulations if they were present in the mature females described by them. Dujardin (1845), on the other hand, mentions them. This leaves it a question as to whether one or more species of Passalurus have been observed up to the time of this report, but $P$. ambiguus is now established as showing a moniliform condition in the female tail. The spicules in both species are about the same size, but they differ slightly in shape. The anal papillae of $P$. nonanulatus are not in agreement with those in the description of $P$. ambiguus given by Danheim and Ackert (1929) and that of Hall (1916); therefore the two species differ in this respect. Danheim and Ackert give the number of these papillae for $P$. ambiguus as five, and so also does Hall. The writer has examined in ventral view many specimens of $P$. nonanulatus and finds only the two pairs of anal papillae as described. Hall (1916) and Danheim and Ackert (1929) agree in reporting for $P$. ambiguus an unpaired papilla located directly behind the cloacal aperture, but among other authors there is little agreement in regard to the number of perianal or adanal papillae assigned to this species. In favorable mounts of $P$. ambiguus the appearance of this "unpaired" papilla is such as to suggest that it represents the fusion of two papillae. Seurat (1916) describes and illustrates three pairs of large perianal papillae and a small pair situated immediately posterior to the cloacal aperture. Von Linstow (1899) describes and illustrates only two pairs of perianal papillae. Dujardin (1845) does not mention any such papillae, and Schneider (1866) indicates only one pair as situated near the cloacal aperture, although another pair is described and illustrated by him as approximately at the side or " fast seitlich stehend." Yorke and Maplestone (1926) describe three pairs of large "pericloacal papillae." The pair of papillae situated at the point

The specimens of this species from the coyote (Oanis lestes) (U. S. N. M. No. 26736) were collected by Dr. E. B. Cram, the intestine of the host having been sent from Olympia, Wash., to the Bureau of Animal Industry by Dr. Glenn R. Bach, formerly of the Bureau of Biological Survey. The presence of Passalurus nonanulatus in a carnivore undoubtedly represents a case of spurious parasitism following the ingestion of the normal host, the hare, by the coyote. 
where the tail narrows in diameter is much less conspicuous in $P$. nonanulatus than in $P$. ambiguus. No caudal alae are present in $P$. nonanulatus.
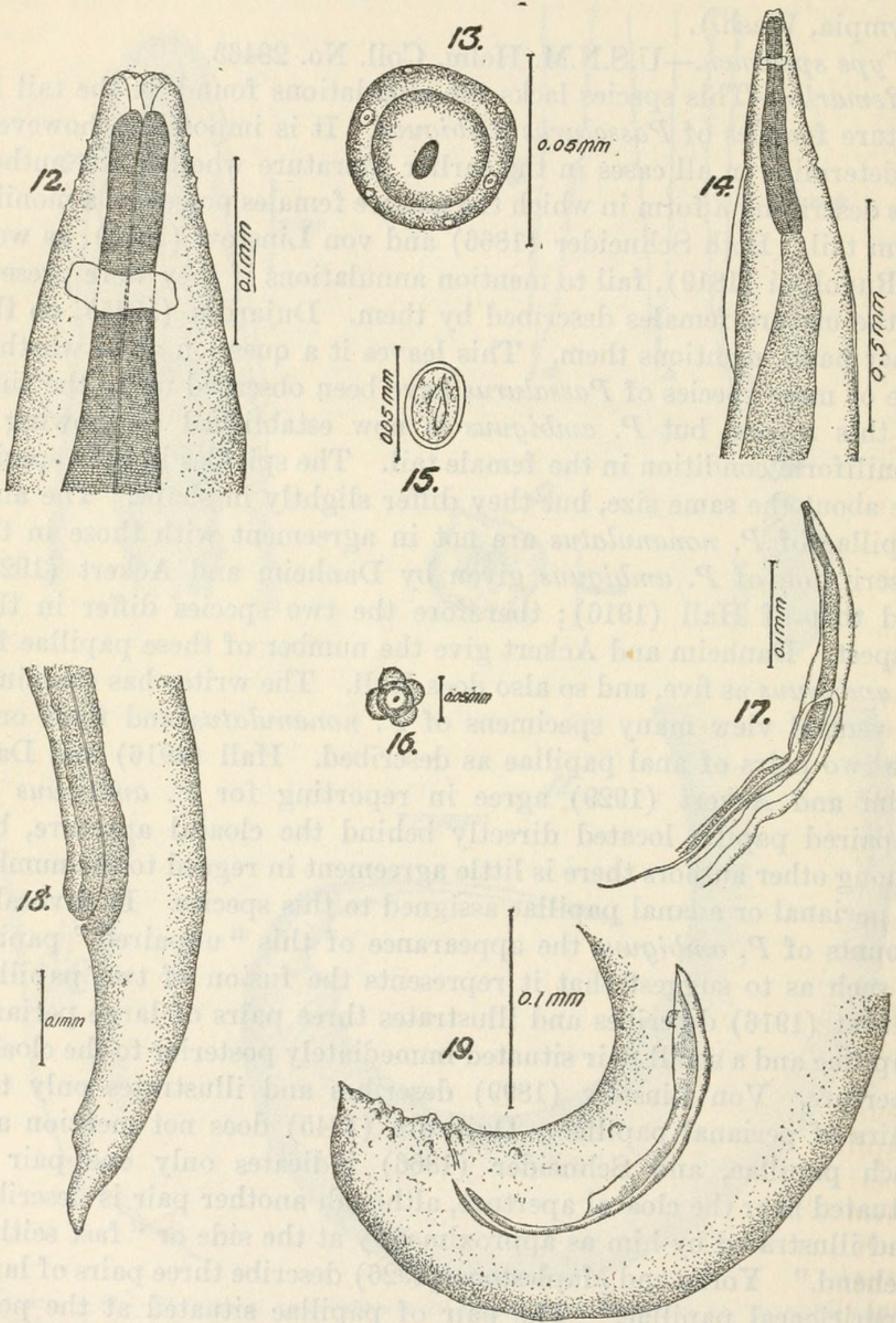

Figures 12-19.-Metathelazia californica: 12, Anterior end of male, showing cervical serrations; 13 , head of male, en face view; 14, anterior end of male; 15 , egg; 16 , anterior view of head, showing the quadripartite condition in the region of the vestibule; 17 , anterior half of male, showing loop in the testis; 18, posterior end of female, showing vulva and anus, lateral view; 19, posterior end of male, lateral view 


\section{Family THELAZIIDAE Railliet, 1916}

\section{METATHELAZIA, new genus}

Generic diagnosis.-Thelaziidae: Mouth without lips but followed by a vestibule in the region of which the body wall is divided by indentations into 4 pillarlike structures giving the quadripartite appearance of the head in anterior view (fig. 16); 4 submedian papillae and 2 amphids; esophagus muscular throughout, enlarged posteriorly, the fibers of this portion being coarser than those of the anterior portion, which gives the appearance of 2 parts to the esophagus. Males with tail bluntly pointed and recurved, without caudal alae; seven pairs of sessile caudal papillae of which four pairs are preanal; spicules equal and transversely striated; gubernaculum present. Females with tail slightly curved and pointed; vulva near anus; uterus apparently double. Oviparous; morulated eggs with a thick shell.

Type species.-Metathelazia californica, new species.

\section{METATHELAZIA CALIFORNICA, new species}

\section{Figures 12 to 19}

Specific diagnosis.-Metathelazia: Cuticle longitudinally striated. Mouth without lips. Diameter of head about $38 \mu$. Four or more cuticular folds or serrations are present in the cervical region. The most anterior fold is situated about $38 \mu$ from the anterior tip of the head and each of the other folds is about $12 \mu$ posterior to the one preceding it. The club-shaped esophagus is $500 \mu$ to $640 \mu$ in length and has a maximum width of about $68 \mu$. The anterior portion is $182 \mu$ to $190 \mu$ in length. The nerve ring is about $122 \mu$ from the anterior end.

Male, $6.6 \mathrm{~mm}$. long with a maximum diameter of $352 \mu$. The esophagus is $502 \mu$ in length and has a maximum diameter of $72 \mu$. Of the seven pairs of caudal papillae, three pairs are postanal. The testis is a prominent structure originating about midway between the anterior and the posterior ends of the body. It passes anteriorly to a point about one-sixth of the distance from the anterior end where it forms a loop and passes posteriorly to the region of the cloaca. The spicules are equal, $225 \mu$ long, their greatest width being $25 \mu$. The gubernaculum is crescent shaped and about $42 \mu$ long.

Female, much larger than the male; estimated from fragments procured from the lynx, the total length of the mature female is about $20 \mathrm{~mm}$. or longer. Maximum width about $241 \mu$; the width at the anus about $76 \mu$. The anus is about $110 \mu$ from the posterior end of the body and the vulva about $320 \mu$ from the end. The ovary appears 
to be double. The eggs are numerous and thick shelled, $38 \mu$ to $40 \mu$ long by $25 \mu$ to $30 \mu$ wide. Most of them are in the morula stage, while in those most fully developed the vitelline membrane is shrunken away from the shell, thus concealing the details of the stage of development reached. No further details could be determined from the fragmentary specimens.

Hosts.-Primary: Lynx (Lynx rufus californicus), puma (Felis hippolestes); secondary: Unknown.

Location.-Lungs.

Distribution.-United States (Lassen County, Calif., and Las Vegas, N. Mex.)

Type specimen.-U. S. N. M. Helm. Coll. No 25337.

Remarks.-The genus to which Metathelazia is most closely related is Thelazia. The two genera are similar in the following characters: The mouth is without lips; a buccal capsule or vestibule is present; the esophagus is moderately short; the tail of the male is recurved and is without caudal alae; cervical serrations are present.

The genus Metathelazia may be distinguished from the genus Thelazia by the fact that in the former the vulva is in the posterior region of the body, the spicules are equal, the preanal papillae are limited to four pairs, the cervical serrations are less conspicuous and fewer in number, and the members of the genus are found in the lungs of mammals.

\section{BIBLIOGRAPHY}

Danheim, Bertha L., and Ackert, James E.

1929. On the anatomy of the nematode Passalurus ambiguus (Rudolphi). Trans. Amer. Micr. Soc., vol. 48, pp. 80-83, January.

Dujardin, Felix.

1845. Histoire naturelle des helminthes ou vers intestinaux. $x v i+654+15$ pp., 12 pls. Paris.

Hall, MaURice C.

1916. Nematode parasites of mammals of the orders Rodentia, Lagomorpha, and Hyracoidea. Proc. U. S. Nat. Mus., vol. 50, pp. 1-258, pl. 1, fig. 290, May 13.

Linstow, OtTo Friedrich Bernhard von.

1899. Nematoden aus der berliner zoologischen Sammlung. Mitt. a. d. Zool. Samml. d. Mus. f. Naturk in Berlin, vol. 1, no. 2, pp. 3-28, pls. 1-6, figs. 1-78.

RUdolphi, Carl Asmund.

1819. Entozoorum synopsis cui accedunt mantissa duplex et indices locupletissimi. $\mathrm{x}+811 \mathrm{pp} ., 3$ pls. Berlin.

SOHNEIDER, ANTON.

1866. Monographie der Nematoden. viii+375 pp., 122 figs., 28 pls., 343 figs. Berlin. 
Seurat, L. G.

1916. Sur les oxyures des mammifères. Compt. rend. Soc. Biol., vol. 69, no. 2, pp. 64-68, Jan. 22.

TAYLOR, E. L.

1925. Notes on some nematodes in the museum of the Liverpool School of Tropical Medicine II. Ann. Trop. Med. and Parasit., vol. 19, pp. 60-67, Mar. 31.

Ward, Henry B., and Magath, Thomas B.

1916. Notes on some nematodes from fresh-water fishes. Journ. Parasitol., vol. 3, pp. 57-64, December.

Yorke, WarRington, and Maplestone, P. A.

1926. The nematode parasites of vertebrates. With a foreword by $\mathrm{d}$. W. Stiles. xi+536 pp., 307 figs. London. 


\section{$2 \mathrm{BHL}$ Biodiversity Heritage Library}

Skinker, Mary Scott. 1931. "Three new parasitic nematode worms." Proceedings of the United States National Museum 79(2890), 1-9. https://doi.org/10.5479/si.00963801.79-2890.1.

View This Item Online: https://www.biodiversitylibrary.org/item/32383

DOI: https://doi.org/10.5479/si.00963801.79-2890.1

Permalink: https://www.biodiversitylibrary.org/partpdf/92593

\section{Holding Institution}

Smithsonian Libraries

\section{Sponsored by}

Smithsonian

\section{Copyright \& Reuse}

Copyright Status: NOT_IN_COPYRIGHT

Rights: https://www.biodiversitylibrary.org/permissions/

This document was created from content at the Biodiversity Heritage Library, the world's largest open access digital library for biodiversity literature and archives. Visit BHL at https://www.biodiversitylibrary.org. 